\title{
ARA-C associated pulmonary toxicity
}

\section{ARA-C ilişkili akciğer toksisitesi}

\author{
Zeynep Arzu Yegin ${ }^{1}$, Gülsan Türköz Sucak ${ }^{1}$, Gonca Erbaş², Münci Yağcl ${ }^{1}$ \\ 'Department of Hematology, Faculty of Medicine, Gazi University, Ankara, Turkey \\ ${ }^{2}$ Department of Radiology, Faculty of Medicine, Gazi University, Ankara, Turkey
}

\section{To the Editor,}

Cytosine arabinoside (ARA-C) associated pulmonary toxicity is a well-described life-threatening complication of anti-leukemia therapy. We previously reported a 17-year-old acute leukemia patient that experienced non-cardiogenic pulmonary edema (NCPE) that was most probably due to highdose ARA-C. Initial respiratory symptoms and fever appeared on the fourth day of ARA-C infusion. High resolution computed tomography (HRCT) showed bilateral pleural effusion with diffuse ground-glass opacity. The clinical course was rigorous, leading to acute respiratory distress syndrome (ARDS) that favorably responded to prompt steroid administration [1]. Chagnon et al. reported 6 acute myeloid leukemia patients treated with intermediate- to high-dose ARA-C that developed a new pattern of pulmonary toxicity described as hypersensitivity pneumonitis [2].

Drug-induced pulmonary damage is an entity encompassing a broad spectrum of pulmonary syndromes with mild to severe symptomatology, including pneumonitis/fibrosis, hypersensitivity pneumonitis, NCPE, and ARDS [3]. ARA-C-induced pulmonary injury is usually overlooked among the turbu- lent circumstances of febrile leukemia patients. ARA-C was suggested to be a causative agent of distinct forms of pulmonary toxicity in several reports [1,3-8]. The primary cause of ARA-C toxicity is considered to be a clinical consequence of cytokine network activation, which results in alveolar damage and increased vascular permeability, leading to capillary leakage syndrome [5,6,9]. The primary characteristics of ARA-C associated pulmonary toxicity are summarized in the Table 1 .

Chagnon et al. based their diagnosis of hypersensitivity pneumonitis primarily on radiological findings; however, radiological findings in a variety of clinical conditions that share a similar radiological appearance and also mimic the general perspective may be difficult to differentiate. Above all, considering the confusing diagnostic possibilities, including opportunistic infections, congestive heart failure, and transfusion-related acute lung injury, and several toxic agents, exact diagnosis of hypersensitivity pneumonitis should rely primarily on characteristic HRCT features and lymphocytosis in bronchoalveolar lavage, so as to minimize the likelihood of misdiagnosis. The diagnosis of hypersensitivity pneumonitis seems to be uncertain; only 2 patients that met the minimum requisite diagnostic 
Table 1 . The primary characteristics of ARA-C associated pulmonary toxicity $(3,4,6,8,9)$

\begin{tabular}{|c|c|}
\hline Median age & 39 years \\
\hline Incidence & $12 \%-20 \%$ \\
\hline ARA-C dose & $\begin{array}{l}\text { Intermediate/high } \\
\cdot 1-1.5 \mathrm{~g} \mathrm{~m}^{-2} / \text { continuous infusion } \\
\cdot>3 \mathrm{~g} \mathrm{~m}^{-2} \text { as } 2 \text {-h iv infusion per } 12 \mathrm{~h}\end{array}$ \\
\hline Day of onset & $\begin{array}{l}\text { 1-2 weeks after chemotherapy } \\
\text { - Usually during the initial course } \\
\text { - Increased risk with multiple doses }\end{array}$ \\
\hline Pathophysiology & Increased alveolar capillary permeability \\
\hline Diagnosis & $\begin{array}{l}\text { Exercise of exclusion } \\
\text { - Heart dysfunction } \\
\text { - Infections } \\
\text { - Metabolic abnormalities } \\
\text { - Cancer-related causes }\end{array}$ \\
\hline Common clinical symptoms & $\begin{array}{l}\text { Early onset of fever } \\
\text { Dyspnea } \\
\text { Hypoxemia } \\
\text { Tachypnea } \\
\text { Cough }\end{array}$ \\
\hline Radiological findings & $\begin{array}{l}\text { X-ray: Confluent alveolar consolidation } \\
\text { HRCT: Alveolar or interstitial opacification in lower lobes surrounded by } \\
\text { ground glass areas and/or pleural effusions }\end{array}$ \\
\hline Treatment & $\begin{array}{l}\text { Steroids: Response rate is } 65 \%-80 \% \\
\text { Supportive care }\end{array}$ \\
\hline
\end{tabular}

ARA-C: cytosine arabinoside; h: hour; HRCT: high resolution computed tomography; iv: intravenous

criteria have been reported. Moreover, early onset of clinically evident pulmonary syndrome described in the paper might contradict the diagnosis of hypersensitivity pneumonitis, as it typically develops as a result of chronic antigenic exposure. Although the clinical condition of the patients was self-limited and they recovered without specific treatment, a longer follow-up period may be necessary for evaluation of the progress of respiratory functions when hypersensitivity pneumonitis is the definitive diagnosis $[2,10]$.

Cytokine storm-induced pulmonary damage, which occasionally leads to a more specific immunological response, appears to be the primary causative mechanism of ARA-C associated pulmonary toxicity, irrespective of clinical presentation. Thus, in addition to early recognition of pulmonary toxicity and immediate withdrawal of chemotherapy, steroids and supportive care are reported to be com- mon therapeutic approaches. It might be misleading to refer to this toxicity as hypersensitivity pneumonitis, as there is currently no supportive evidence.

To summarize, we suggest that the wide spectrum of clinical presentation associated with ARA-C might have a common underlying mechanism, which triggers the cytokine network. ARA-C associated pulmonary toxicity might be a more comprehensive term to describe this clinical picture, which has several predisposing factors. We think the main point is to consider ARA-C in the differential diagnosis of mild to severe pulmonary symptoms in leukemia patients and to treat it appropriately, rather than describing the different clinical presentations with distinct clinical terms.

\section{Conflict of interest statement}

None of the authors of this paper has a conflict of interest, including specific financial interests, rela- 
tionships and/or affiliations relevant to the subject matter or materials included.

\section{References}

1. Yegin ZA, Akı S, Sucak G, Yagcı M. Cytarabine induced non cardiogenic pulmonary edema in a case of acute lymphoblastic leukemia. Int J Lab Hem 2007;29: 482-3. [CrossRef]

2. Chagnon K, Boissel N, Raffoux E, Dombret H, Tazi A, Bergeron A. A new pattern of cytosine arabinoside induced lung toxicity. $\mathrm{Br} \mathrm{J}$ Haematol 2009;147: 760-74. [CrossRef]

3. Briasoulis E, Pavlidis N. Non cardiogenic pulmonary edema: An unusual and serious complication of anticancer therapy. Oncologist 2001;6:153-61. [CrossRef]

4. Andersson BS, Cogan BM, Keating MJ, Estey EH, McCredie KB, Freireich EJ. Subacute pulmonary failure complicating therapy with high dose ARA-C in acute leukemia. Cancer 1985;56:2181-4. [CrossRef]

5. Andersson BS, Luna MA, Yee C, Hui KK, Keating MJ, McCredie KB. Fatal pulmonary failure complicating high dose cytosine arabinoside therapy in acute leukemia. Cancer 1990;65:1079-84. [CrossRef]

6. Forghieri F, Luppi M, Morselli M, Potenza L, Volzone F, Riva G, Imovilli A, Rivolti E, Torelli G. Cytarabine related lung infiltrates on high resolution computerized tomography: a possible complication with benign outcome in leukemic patients. Haematologica 2007;92:85-90. [CrossRef]

7. Larouche G, Denault A, Prenovault J. Corticosteroids and serious cytarabine-induced pulmonary edema. Pharmacotherapy 2000;20:1396-9.

8. Salvucci M, Zanchini R, Molinari AL, Zuffa E, Poletti V, Poletti G, Zaccaria A. Lung toxicity following fludarabine, cytosine arabinoside and mitoxantrone (FLAN) treatment for acute leukemia. Haematologica 2000;85:769-70.

9. Chiche D, Pico JL, Bernaudin JF, Chouaib S, Wollman E, Arnoux A, Denizot Y, Nitenberg G. Pulmonary edema and shock after high dose aracytine-C for lymphoma; possible role of TNF-alpha and PAF. Eur Cytokine Network 1993;4:147-51.

10. HirshmannJV,PipavathSNJ, GodwinJD. Hypersensitivity pneumonitis: A historical, clinical and radiologic review. Radiographics 2009;29:1921-38. [CrossRef] 